\title{
REGULAÇÃO DA ABSORÇÃO E ASSIMILAÇÃO DO NITROGÊNIO NAS PLANTAS
}

\author{
REGULATION OF NITROGEN ABSORTION AND ASSIMILATION IN PLANTS
}

\author{
Christian Bredemeier $^{1}$ Claudio Mario Mundstock ${ }^{2}$
}

\section{- REVISÃO BIBLIOGRÁFICA -}

\section{RESUMO}

A presente revisão tem por objetivo discutir os mecanismos de regulação da absorção e assimilação do nitrogênio nas plantas, de modo que a eficiência de uso desse nutriente seja aumentada. O nitrogênio é absorvido nas raízes sob a forma de $\mathrm{NO}_{3}^{-}$ou $\mathrm{NH}_{4}^{+}$, sendo então incorporado em aminoácidos na própria raiz ou na parte aérea. A taxa e a quantidade de nitrogênio absorvido e assimilado durante o ciclo da planta dependem da presença de carregadores específicos na membrana plasmática, da atividade das enzimas envolvidas no seu ciclo, da disponibilidade de energia necessária para os processos de absorção e assimilação e do estádio de desenvolvimento da planta. Inúmeros grupos de pesquisa têm centrado esforços na identificação dos pontos mais limitantes do metabolismo do nitrogênio nas plantas. Os limitadores têm sido relacionados com: a) a afinidade dos carregadores pelo nitrato e amônio; b) o suprimento de carboidratos às raízes; c) o nível de aminoácidos no floema radicular; d) a atividade das enzimas redutase do nitrato (RN), sintetase da glutamina $(G S)$ e sintase do glutamato (GOGAT); e) a fonte de $N$ suprida às plantas $\left(\mathrm{NO}_{3}{ }^{-}\right.$ou $\left.\mathrm{NH}_{4}^{+}\right) ; f$ ) o local de assimilação do $\mathrm{N}$ (raiz ou parte aérea). Esses estudos têm mostrado que o metabolismo do $N$ é multiregulado e integrado ao metabolismo geral da planta. A identificação de pontos metabólicos específicos que são mais limitantes para o incremento da produtividade é complexa. A perspectiva é que a clonagem dos transportadores de $N$ poderá auxiliar os programas de melhoramento genético na obtenção de plantas mais eficientes na absorção do nitrogênio.

Palavras-chave: nitrogênio, absorção, assimilação, regulação.

\section{SUMMARY}

Nitrogen is absorbed as $\mathrm{NO}_{3}^{-}$or $\mathrm{NH}_{4}^{+}$and assimilated into aminoacids both in roots and shoots. Root absortion (rate and total amount) at each plant developmental stage depends on specific plasma membrane carriers, enzyme activity for reduction and assimilation and energy availability for

\begin{abstract}
both processes. Several research groups are trying to identify bottlenecks on nitrogen metabolism processes. The main limitations referred are: a) Carriers affinity for nitrate and amonium, b) Carbohydrate supply to roots, c) Phloem aminoacids level concentration, d) Nitrate reductase (NR), glutamine synthetase (GS) and glutamate synthase (GOGAT) enzyme activity, e) $\mathrm{N}$ source $\left(\mathrm{NO}_{3}^{-}\right.$or $\left.\mathrm{NH}_{4}^{+}\right)$supplied, and $f$ ) Site of assimilation (root or shoot). These studies are showing that $N$ metabolism is multi-regulated and integrated to plant general metabolism. The identification of specific metabolic steps that limit plant productivity is very complex. Cloning specific $N$ carriers may help breeding programs in order to get more nitrogen efficient plants.
\end{abstract}

Key words: nitrogen, absortion, assimilation, regulation.

\section{INTRODUÇÃO}

O nitrogênio $(\mathrm{N})$ é considerado elemento essencial para as plantas, pois está presente na composição das mais importantes biomoléculas, tais como ATP, NADH, NADPH, clorofila, proteínas e inúmeras enzimas (MIFLIN \& LEA, 1976; HARPER, 1994). Em muitos sistemas de produção, a disponibilidade de nitrogênio é quase sempre um fator limitante, influenciando o crescimento da planta mais do que qualquer outro nutriente.

Dada a sua importância e a alta mobilidade no solo, o nitrogênio tem sido intensamente estudado, no sentido de maximizar a eficiência do seu uso. Para tanto, tem-se procurado diminuir as perdas do nitrogênio no solo, bem como melhorar a absorção e a metabolização do N no interior da planta.

\footnotetext{
${ }^{1}$ Engenheiro Agrônomo. Professor Substituto do Departamento de Plantas de Lavoura (DPL), Faculdade de Agronomia, Universidade Federal do Rio Grande do Sul (UFRGS), CP 776, 90001-970, Porto Alegre, RS. E-mail: bredemeier@netmarket.com.br. Autor para correspondência.

${ }^{2}$ Engenheiro Agrônomo. PhD., Professor Titular do DPL, UFRGS. 
A eficiência da utilização do nitrogênio adicionado ao solo se refere ao grau de recuperação desse elemento pelas plantas, considerando as perdas que geralmente ocorrem. Normalmente, menos de $50 \%$ do nitrogênio aplicado sob a forma de fertilizante é utilizado pelas culturas. As perdas no solo são devido aos inúmeros processos aos quais o nitrogênio está sujeito. O nitrogênio é perdido principalmente pela lixiviação de nitrato, volatilização de amônia e emissão de $\mathrm{N}_{2}, \mathrm{~N}_{2} \mathrm{O}$ e outros óxidos de nitrogênio (ANGHINONI, 1986).

A eficiência na utilização do $\mathrm{N}$ pela planta considera os aspectos de absorção e metabolização deste elemento. Esta revisão aborda o metabolismo do nitrato e do amônio e discute as principais regulações metabólicas relacionadas à absorção e assimilação do nitrogênio nas plantas e os mecanismos de regulação do metabolismo do $\mathrm{N}$ na planta durante o seu ciclo. Também visa a abordar a situação atual da pesquisa e perspectivas direcionadas para o aumento da eficiência no aproveitamento do nitrogênio pelas plantas.

\section{A ABSORÇÃo E A ASSIMILA- ÇÃO DO NITROGÊNIO NAS RAÍZES E FOLHAS}

A passagem de nitrato $\left(\mathrm{NO}_{3}{ }^{-}\right)$e amônio $\left(\mathrm{NH}_{4}^{+}\right)$através da membrana plasmática (plasmalema) das células da epiderme e do córtex da raiz ocorre através de transportadores específicos para essas formas de nitrogênio (LARSSON \& INGEMARSSON, 1989). A figura 1 mostra que, após a sua entrada na célula, o nitrato pode ser reduzido a nitrito $\left(\mathrm{NO}_{2}{ }^{-}\right)$, no citosol, através da enzima redutase do nitrato $(\mathrm{RN})$ e, $\log$ a a seguir, convertido a amônio $\left(\mathrm{NH}_{4}{ }^{+}\right)$no plastídio, através da enzima redutase do nitrito $(\mathrm{RNi})$. O amônio é, então, incorporado em aminoácidos pelas enzimas sintetase da glutamina (GS) e sintase do glutamato (GOGAT), formando glutamina (GLN), glutamato (GLU) e outros aminoácidos e seus metabólitos (CRAWFORD, 1995). Alternativamente, o $\mathrm{NO}_{3}^{-}$e o $\mathrm{NH}_{4}^{+}$podem ser transportados por carregadores específicos através do tonoplasto e armazenados no vacúolo, para posteriormente serem reduzidos no citosol da mesma célula ou serem translocados inalterados para a parte aérea da planta (Figura 1). Nos colmos e folhas (Figura 1.a), o nitrato é reduzido a nitrito pela ação da enzima RN, e a amônio, através da enzima RNi. O amônio é então incorporado em aminoácidos pelas enzimas GS e GOGAT. Estes elementos também são armazenados no vacúolo das células para posterior redução e utilização (KING et al., 1993; CRAWFORD, 1995).

\section{REGULAÇÃO DA ABSORÇÃO DO NITROGÊ- NIO PELAS RAÍZES}

\section{a) Transporte através das membranas}

A absorção de $\mathrm{N}$ através da membrana plasmática é mediada por dois tipos de carregadores (SIDDIQI $\boldsymbol{e}$ t al., 1990; LEA, 1993; VON WIRÉN $\boldsymbol{e} t$ al., 1997). Os carregadores de baixa afinidade (Low Affinity Transport System - LATS) operam quando

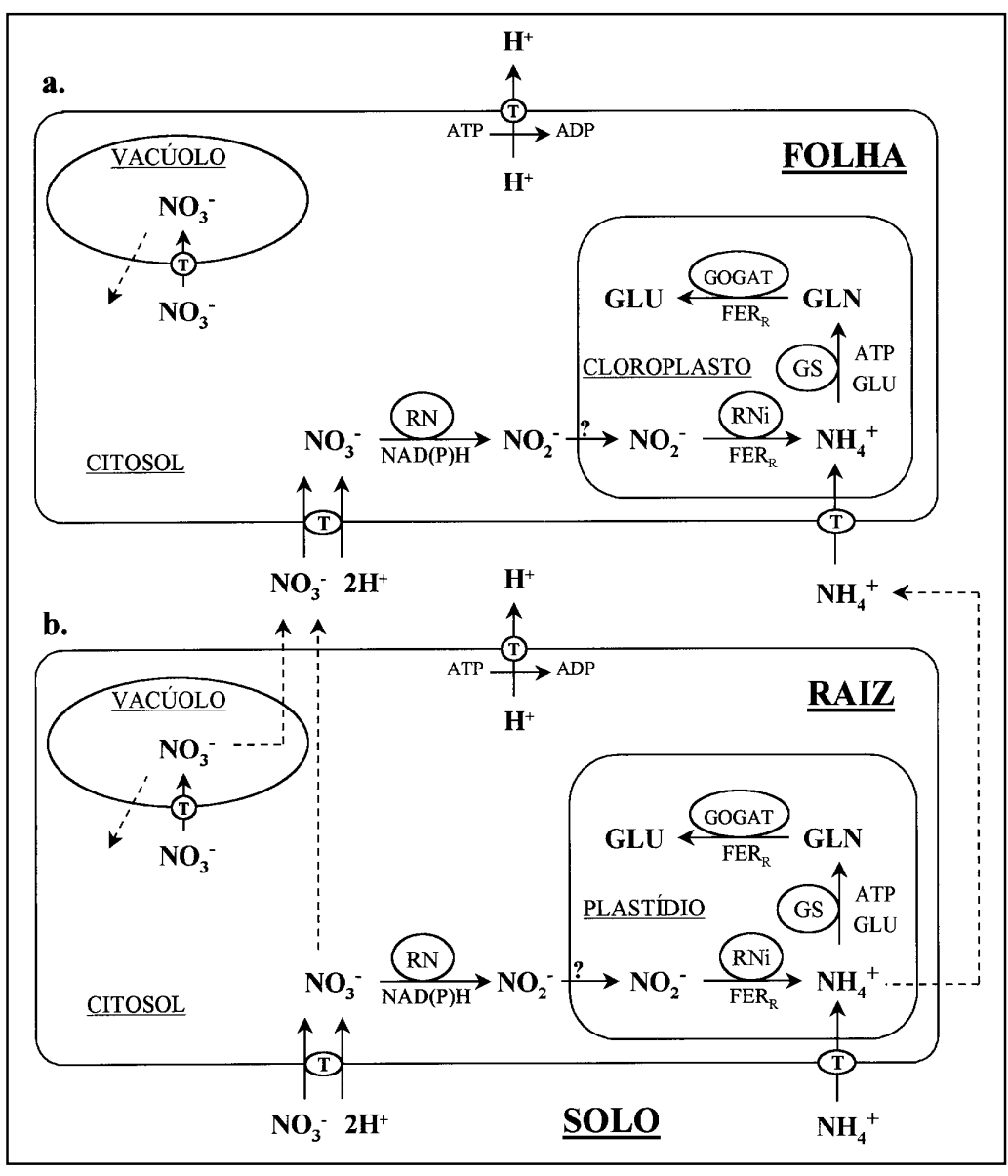

Figura 1 - Representação esquemática da rota de assimilação do nitrogênio nas raízes e folhas de plantas. $\left(\mathrm{NO}_{3}{ }^{-}\right.$: nitrato; $\mathrm{NO}_{2}{ }^{-}$: nitrito; $\mathrm{NH}_{4}{ }^{+}$: amônio; GLN: glutamina; GLU: glutamato; RN: redutase do nitrato; RNi:redutase do nitrito; GS: sintetase da glutamina; GOGAT: sintetase do glutamato; T: transportador). 
a concentração externa de $\mathrm{N}$ é alta e são caracterizados por serem constitutivos e não sujeitos à regulação. Os carregadores de alta afinidade (High Affinity Transport System - HATS) atuam sob baixas concentrações externas de $\mathrm{N}$ e podem ser constitutivos (Constitutive High Affinity Transport System - CHATS) ou induzidos pela exposição ao N (Inducible High Affinity Transport System IHATS) (ASLAM $\boldsymbol{e}$ t al., 1992; LEA, 1993; VON WIRÉN et al., 1997). Para o nitrato, sob concentrações externas inferiores que $100-200 \mu \mathrm{mol} \ell^{-1}$, o transporte pela membrana ocorre via carregadores de alta afinidade (HATS), com um $\mathrm{K}_{\mathrm{m}}$ entre $7 \mathrm{e}$ $100 \mu \mathrm{mol} \ell^{-1}$. Acima destas concentrações, a absorção de nitrato ocorre pelos carregadores de baixa afinidade (LATS), com $\mathrm{K}_{\mathrm{m}}$ maior que $0,5 \mathrm{mmol} \ell^{-1}$ (VON WIRÉN et al., 1997). Para o amônio, a absorção é mediada pelo HATS quando a concentração externa deste íon é menor que $1 \mathrm{mmol} \ell^{-1}$, enquanto que o LATS é responsável pela absorção de amônio em concentrações externas superiores a $1 \mathrm{mmol} \ell^{-1}$ (VON WIRÉN et $\boldsymbol{a l}$., 1997). A absorção de N é, portanto, modulada pela: a) presença dos carregadores específicos; b) pela afinidade desses carregadores em relação ao nitrato ou amônio; c) pela quantidade de $\mathrm{N}$ presente no solo.

\section{b) Modulação da absorção durante o ciclo da planta}

A quantidade de nitrogênio absorvida varia durante o ciclo de desenvolvimento da planta em função da quantidade de raízes e da taxa de absorção por unidade de peso de raiz (moles $\mathrm{NO}_{3}^{-}$ou $\mathrm{NH}_{4}^{+} \mathrm{h}^{-1} \mathrm{~g}^{-1}$ raiz). Normalmente, essa quantidade aumenta progressivamente durante o período de crescimento vegetativo, atinge o máximo durante os estádios reprodutivos e cai na fase de enchimento dos grãos (CREGAN \& BERKUM, 1984). Essa flutuação durante a ontogenia da planta é, em parte, explicada pela disponibilidade de nitrogênio no solo, mas fatores intrínsecos à planta têm papel relevante nesse processo. Entre esses, têm sido sugeridos os mecanismos do ciclo de aminoácidos entre o colmo e a raiz e o suprimento de carboidratos às raízes.

\section{Ciclo de aminoácidos entre o colmo e raiz.}

O mecanismo segundo o qual o nível de aminoácidos no floema da raiz regula a absorção e a assimilação de nitrogênio pela planta foi sugerido por IMSANDE \& TOURAINE (1994). Ele é embasado na constatação de que, durante o rápido crescimento vegetativo, são altas as taxas de redução de nitrato e síntese de aminoácidos nas folhas. Ali mesmo, é utilizada a maioria dos aminoácidos para a síntese de clorofila, rubisco e outras proteínas e, com isso, é baixo o nível de aminoácidos no floema que entra nas raízes (Figura 2.a).

Por outro lado, durante a fase reprodutiva, diminui a taxa de redução de nitrato; em paralelo, em função da remobilização do $\mathrm{N}$ foliar para o desenvolvimento das inflorescências, aumenta a exportação de aminoácidos das folhas, enriquecendo, com esses compostos, o floema que entra nas raízes (Figura 2.b). O mecanismo proposto sugere que esses aminoácidos provocam uma redução na taxa de absorção de $\mathrm{NO}_{3}^{-}$(IMSANDE \& TOURAINE, 1994).

A ação dos aminoácidos sobre a absorção de $\mathrm{N}$ ainda não é conhecida. Provavelmente, os altos níveis de aminoácidos nas raízes inibem a ação dos transportadores de $\mathrm{NO}_{3}{ }^{-}$na membrana (IMSANDE \& TOURAINE, 1994) e a síntese da enzima redutase do nitrato (LEA, 1997).

\section{Suprimento de carboidratos às raízes}

A absorção de nitrogênio pode ser modulada pela disponibilidade energética para os proces-

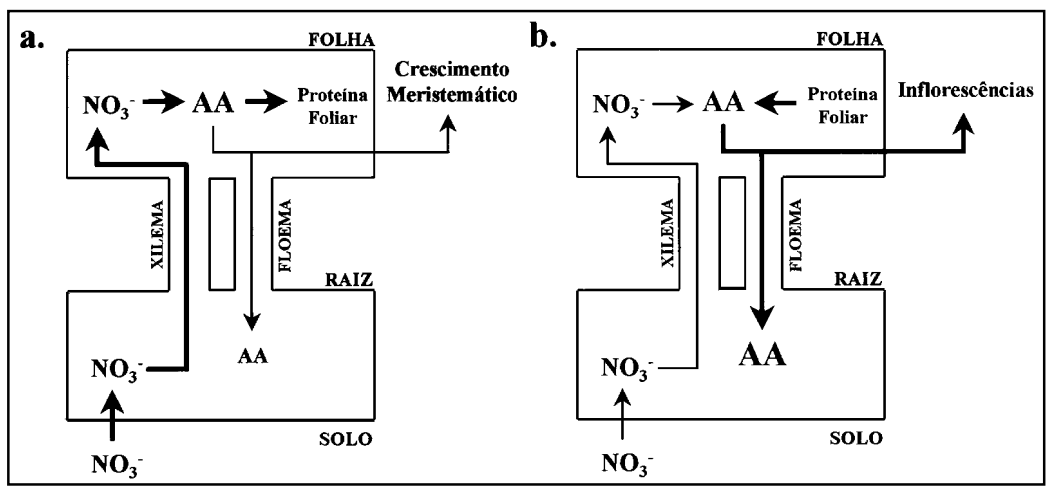

Figura 2 - Modelo de controle da taxa de absorção de nitrogênio durante rápido crescimento vegetativo (a) e enchimento de grãos (b). Durante o crescimento vegetativo (a), o nitrogênio é rapidamente absorvido pelas raízes e transportado para as folhas. Nas folhas, a redução do nitrato produz aminoácidos (AA), os quais são incorporados à proteína foliar. Durante o enchimento de grãos (b), ocorre a remobilização do $\mathrm{N}$ foliar e a exportação de aminoácidos é alta. Conseqüentemente, o floema fica enriquecido com AA, o que inibe a absorção e a redução de nitrato nas raízes (Adaptado de IMSANDE \& TOURAINE, 1994). 
sos de transporte de íons pelas membranas, os quais são dependentes de energia. Ela é necessária para que a bomba de prótons $\mathrm{H}^{+}$-ATPase, presente na membrana, bombeie íons $\mathrm{H}^{+}$para fora da célula (Figura 1), produzindo um gradiente eletroquímico (CRAWFORD, 1995). Esse gradiente é necessário para que os transportadores transfiram o nitrato para dentro da célula, cotransportando dois ou mais prótons por unidade de $\mathrm{NO}_{3}^{-}$(Figura 1) (ULLRICH \& NOVACKY, 1990, CRAWFORD, 1995).

Os carboidratos provindos da parte aérea disponibilizam a energia para esse processo, como mostrado por HUPPE \& TURPIN (1994) em trigo. Eles mostraram que a capacidade das raízes em absorver nitrogênio esteve diretamente correlacionada com o suprimento de carboidratos. Isso explica, em parte, a variação diária na taxa de absorção de $\mathrm{N}$ nas plantas em função da maior disponibilidade de carboidratos na presença de luz (RUFTY et al., 1989).

Nesse mesmo sentido, um estudo detalhado foi realizado em soja por TOURAINE $\boldsymbol{e t} \boldsymbol{a l}$. (1992), incrementando (adição de malato) ou diminuindo (corte do hipocótilo) o suprimento de carboidratos às raízes. A adição de malato ao meio de cultivo praticamente dobrou a taxa de absorção de $\mathrm{NO}_{3}{ }^{-}$e o corte do hipocótilo resultou na diminuição gradativa da taxa de absorção de nitrato, ambos os tratamentos afetando a disponibilidade energética.

O suprimento de energia também é modificado quando é alterada a taxa de translocação de carboidratos para as raízes. Por exemplo, no decorrer do desenvolvimento de uma planta, quando há a emissão de uma nova folha, grande parte dos carboidratos é direcionada para o desenvolvimento do novo orgão (VESSEY et al., 1990). Paralelamente, há uma diminuição na taxa de translocação desses compostos para o sistema radicular, diminuindo a disponibilidade de energia nas raízes, o que reduz a taxa de absorção de nitrogênio. Em conseqüência, a oscilação da taxa de absorção de $\mathrm{N}$ durante o ciclo da planta é sincronizada com a emergência de novas folhas (VESSEY et al., 1990).

\section{REGULAÇ̃̃O DA ASSIMILAÇÃO DO NITROGÊNIO}

A assimilação do $\mathrm{N}$ compreende os processos de redução do nitrato a amônio e a incorporação do amônio em aminoácidos. A taxa e a quantidade de nitrogênio assimilado pelas plantas durante o seu ciclo dependem da atividade das enzimas envolvidas no ciclo do nitrogênio e da disponibilidade de energia necessária para os processos de assimilação.

\section{a) Regulação pelas enzimas do ciclo do nitrogênio}

\section{Redutase do nitrato $(R N)$}

A RN foi considerada enzima chave na regulação do metabolismo de $\mathrm{N}$ na década de 70 (BEEVERS \& HAGEMAN, 1969), em razão que o nitrato absorvido pelas raízes deve ser reduzido a amônio antes de ser incorporado em compostos orgânicos, seja no sistema radicular, seja na parte aérea (Figura 1). Ela é a primeira enzima na cadeia de redução do nitrogênio dentro do processo de assimilação do $\mathrm{N}$ nas plantas (PURCINO et al., 1994). Por causa desse seu papel regulador, a atividade da RN poderia estar relacionada, indiretamente, com a produtividade das culturas. Isso com base na pressuposição de que plantas com alta atividade da $\mathrm{RN}$ teriam maior capacidade de assimilar o nitrato disponível e, em conseqüência, maior capacidade em responder à adubação nitrogenada (BEEVERS \& HAGEMAN, 1969). Vários trabalhos experimentais foram conduzidos para testar essa hipótese e para avaliar a possibilidade de se utilizar a atividade dessa enzima como ferramenta auxiliar no desenvolvimento de genótipos mais produtivos ou mais eficientes no uso do nitrogênio (HAGEMAN et al., 1967; HAGEMAN \& LAMBERT, 1988; PURCINO et al., 1994; MACHADO \& MAGALHÃES, 1995).

Esses trabalhos tiveram início no final da década de 60, na Universidade de Illinois (EUA), através das pesquisas desenvolvidas por R.H. Hageman, que avaliou a possibilidade de selecionar híbridos de milho mais produtivos em função da maior atividade da RN. Essa linha de pesquisa foi desenvolvida com base no trabalho de BEEVERS \& HAGEMAN (1969), que verificaram o aumento da atividade da $\mathrm{RN}$ com a adição de $\mathrm{NO}_{3}{ }^{-}$ao meio de cultivo em inúmeras espécies de plantas. Essa idéia foi reforçada pelas correlações positivas entre produtividade de grãos de híbridos de milho e atividade da RN obtidas por DECKHARD et al. (1973). As correlações, apesar de significativas, foram baixas, indicando que outros fatores, além da atividade da $\mathrm{RN}$, têm forte influência na assimilação de $\mathrm{NO}_{3}{ }^{-}$e na produtividade do milho.

Posteriormente, trabalhos como os de FAKOREDE \& MOCK (1978) e EICHELBERG $\boldsymbol{e}$ t al. (1989) não mostraram aumentos de produtividade de híbridos de milho associados com aumentos na atividade da $\mathrm{RN}$ e concluíram que a atividade da $\mathrm{RN}$ não era um critério adequado para ser utilizado como parâmetro no melhoramento, e tampouco como indicativo de alta eficiência na assimilação do N. Progressivamente, foi sendo descartada a hipóte- 
se que uma alta atividade da RN pudesse ser usada como critério de seleção para a identificação de genótipos mais produtivos. Isso veio ao encontro da proposta de HAGEMAN \& LAMBERT (1988), de que ganhos no rendimento de grãos são pouco prováveis de ocorrer se for usada somente uma particularidade enzimática relacionada ao metabolismo do nitrogênio.

Sintetase da glutamina (GS) / Sintase do glutamato (GOGAT)

O papel da GS e GOGAT no processo de transaminação (Figura 1) foi estabelecido na década de 80, através dos trabalhos de WOO \& OSMOND (1982) e FENTEM et al. (1983). Eles vieram substituir o conceito de que a enzima dehidrogenase do glutamato $(\mathrm{GDH})$ era responsável pela maior parte da incorporação do $\mathrm{NH}_{4}^{+}$no ácido $\alpha$-ceto glutárico, formando o glutamato.

Em razão da inconsistência dos resultados dos trabalhos com a RN, na procura de associação entre atividade enzimática e capacidade de assimilação de $\mathrm{N}$ pelas plantas, foi levantada a hipótese de que a atividade das enzimas GS e GOGAT estaria mais relacionada a essa capacidade. $\mathrm{O}$ pressuposto foi que os genótipos eficientes no uso do nitrogênio são aqueles que têm alta capacidade de incorporar o íon amônio em aminoácidos, através das enzimas GS e GOGAT. Assim, o trabalho de MACHADO et al. (1992) mostrou uma alta correlação $(\mathrm{r}=0.68)$ entre a atividade da enzima GS e a produção de grãos de genótipos de milho. Esse e outros trabalhos (MACHADO \& MAGALHÃES, 1995; MAGALHÃES \& MACHADO, 1995) indicaram que a determinação da atividade da enzima GS poderia ser utilizada como um parâmetro auxiliar na seleção de genótipos mais eficientes na utilização do nitrogênio. É importante destacar que existe variabilidade genética para essa característica (MACHADO $\boldsymbol{e} \boldsymbol{t} \boldsymbol{a l}$., 1992; MAGALHÃES $\boldsymbol{e} \boldsymbol{t} \boldsymbol{a l}$. 1993). O uso generalizado desse parâmetro, no entanto, fica limitado pelo fato de que a assimilação do amônio em aminoácidos só é limitante quando somente essa forma de $\mathrm{N}$ é suprida às raízes e/ou quando a quantidade absorvida excede a capacidade assimilatória da planta (HARPER, 1994).

\section{b) Regulação pela disponibilidade energética}

A exigência energética da assimilação do nitrogênio varia em função da fonte de nitrogênio (nitrato ou amônio) disponível às plantas e dos orgãos da planta onde ele é metabolizado.
Fonte de nitrogênio suprida às raízes $\left(\mathrm{NO}_{3}^{-} \mathrm{ou}\right.$ $\mathrm{NH}_{4}^{+}$)

A assimilação de nitrogênio (Figura 1) é um processo altamente exigente em termos de energia, requerendo a transferência de 2 elétrons por $\mathrm{NO}_{3}{ }^{-}$convertido em $\mathrm{NO}_{2}{ }^{-}, 6$ elétrons por $\mathrm{NO}_{2}{ }^{-}$convertido em $\mathrm{NH}_{4}{ }^{+}$e 2 elétrons e 1 ATP por molécula de $\mathrm{NH}_{4}{ }^{+}$convertida em glutamato (BLOOM et al., 1992). Disso decorre que a assimilação do $\mathrm{NO}_{3}$ demanda mais energia, em comparação à assimilação do $\mathrm{NH}_{4}{ }^{+}$. Isso é indicado por maiores taxas de liberação de $\mathrm{CO}_{2}$ respiratório no processo de assimilação do nitrato (WEGER \& TURPIN, 1989). Essa diferença foi confirmada por BLOOM et al. (1992) em cevada, mostrando que o metabolismo do $\mathrm{NO}_{3}{ }^{-}$consumiu $23 \%$ de toda energia produzida na raiz, em comparação aos $14 \%$ exigidos para o metabolismo do $\mathrm{NH}_{4}{ }^{+}$. A exigência energética da assimilação do amônio é menor do que a exigência energética para a assimilação do nitrato, em razão do primeiro não precisar ser reduzido para sua incorporação em aminoácidos (Figura 1).

$\mathrm{O}$ aproveitamento dessa vantagem energética orientou a criação do programa de seleção de linhagens de milho com maior eficiência na utilização do $\mathrm{NH}_{4}{ }^{+}$no Centro Nacional de Pesquisa de Milho e Sorgo (CNPMS) da EMBRAPA. A pressuposição foi que as plantas supridas com amônio exigem menos energia para crescer e, em decorrência, o número de plantas por área pode ser aumentado, resultando em maior produtividade líquida. Para tanto, as plantas necessitam ter alta atividade da GS e GOGAT e o $\mathrm{NH}_{4}{ }^{+}$deve ser a forma do fertilizante aplicado ao solo e preferencialmente assimilada pela planta. $\mathrm{O}$ fertilizante amoniacal tem vantagens pelo fato do íon amônio ser fortemente adsorvido às partículas de solo (MAGALHÃES $\boldsymbol{e t}$ al., 1993), evitando perdas por lixiviação, e pela redução da exigência energética na assimilação de N. Além disso, o íon amônio parece ser a forma predominante de absorção de $\mathrm{N}$ pelas plantas em condições de stress (MAGALHÃES \& FERNANDES, 1990).

A seleção de genótipos de milho baseia-se na menor acumulação de $\mathrm{NH}_{4}{ }^{+}$livre no tecido (ele é tóxico em altos níveis) e maior atividade da enzima sintetase da glutamina (GS) no tecido verde da planta. Em complemento, os genótipos selecionados são testados em solos com inibidores da nitrificação (MAGALHÃES $\boldsymbol{e t} \boldsymbol{a l}$., 1993; MAGALHÃES \& MACHADO, 1995). Isso é importante, pois o íon de nitrogênio absorvido pelas plantas $\left(\mathrm{NO}_{3}^{-}\right.$ou $\left.\mathrm{NH}_{4}{ }^{+}\right)$ depende das quantidades relativas de cada uma das formas no solo, da acessibilidade das raízes a essas diferentes formas e das preferências da planta (VON 
WIRÉN et al., 1997). Um complicador neste processo é que, na maioria dos casos, a manutenção do balanço entre cátions e ânions na célula pode determinar a forma de $\mathrm{N}$ preferencialmente absorvida pelas plantas (VAN BEUSICHEM et al., 1988).

\section{Local de assimilação (raiz ou parte aérea)}

O nitrogênio, uma vez absorvido, pode ser assimilado na própria raiz ou ser transportado para as folhas, onde, então, ocorre a sua assimilação. Nas folhas, a energia para as reações de assimilação do nitrogênio (Figura 1) é gerada nos cloroplastos pela fotossíntese, no citosol pela glicólise, e nos mitocôndrios pelo ciclo do ácido tricarboxílico no processo de respiração (OAKS \& HIREL, 1985; HUPPE \& TURPIN, 1994). Nos cloroplastos, as reações catalisadas pelas enzimas redutase do nitrito (RNi) e sintase do glutamato (GOGAT) exigem a redução da ferredoxina, o que é feito pelo sistema de transporte não-cíclico de elétrons (CRAWFORD, 1995).

Quando o nitrogênio é metabolizado nas raízes, a energia é gerada no citosol, através do ciclo das pentoses e da glicólise, e nos mitocôndrios pelo ciclo do ácido tricarboxílico (OAKS \& HIREL, 1985). A ferredoxina, para as reações que envolvem a RNi e a GOGAT, é reduzida no citosol pelo NADPH produzido pelo ciclo das pentoses (CRAWFORD, 1995). Nas raízes, existe a necessidade de importação de carboidratos produzidos nas folhas para, após serem metabolizados, gerar energia e fornecer esqueletos de carbono para o processo de incorporação do nitrogênio em aminoácidos (OAKS E HIREL, 1985; TURPIN et al., 1991; OAKS, 1994).

Um estudo comparativo dos custos energéticos para a conversão de $\mathrm{NO}_{3}{ }^{-}$em glutamato em tecidos verdes (folhas) e em tecidos não-verdes (raízes) foi feito por Schrader \& Thomas, apud HARPER (1994). A assimilação de uma molécula de $\mathrm{NO}_{3}{ }^{-}$em aminoácidos em tecidos não-verdes consumiu a energia equivalente à absorção de 35 fótons, enquanto que nas folhas esse mesmo processo consumiu a energia equivalente à absorção de 20 fótons. Essa vantagem energética é a base da sugestão da seleção de linhagens que maximizem a redução de $\mathrm{NO}_{3}{ }^{-}$nas folhas, visando a reduzir as exigências energéticas e aumentar a produtividade (SCHRADER, 1984).

\section{SITUAÇÃO ATUAL E PERSPECTIVAS DE PESQUISAS FUTURAS}

Atualmente, os esforços da pesquisa para aumentar a eficiência na utilização de nitrogênio pelas plantas estão voltados, principalmente, aos estudos da eficiência das diferentes enzimas e suas isoformas envolvidas no ciclo do $\mathrm{N}$ na planta e à identificação dos transportadores de nitrogênio presentes na membrana plasmática das células. A manipulação dos transportadores de nitrato e amônio abre uma perspectiva de atuar-se diretamente no processo de absorção do nitrogênio pela planta. Para tanto, são necessários o isolamento, a identificação, a caracterização e a clonagem dos genes responsáveis pela expressão dos transportadores de alta afinidade para $\mathrm{NO}_{3}{ }^{-}$e $\mathrm{NH}_{4}{ }^{+}$e transportadores de baixa afinidade para $\mathrm{NO}_{3}^{-}$(CRAWFORD, 1995; HUANG $\boldsymbol{e}$ t al., 1996; TOURAINE \& GLASS, 1997; VON WIRÉN et al., 1997). A perspectiva é que esses conhecimentos possam ser futuramente utilizados em programas de melhoramento genético, visando ao desenvolvimento de genótipos mais eficientes na utilização do nitrogênio disponível no solo.

\section{CONSIDERAÇÕES FINAIS}

A absorção e assimilação de $\mathrm{N}$ pela planta são processos multiregulados e integrados ao metabolismo geral da planta. A multi-regulação do metabolismo do $\mathrm{N}$ torna complexa a identificação de pontos metabólicos específicos que sejam mais limitantes para o incremento da produtividade. A fonte de $\mathrm{N}$ e o local de assimilação podem ser importantes, especialmente em condições de crescimento nas quais a disponibilidade de energia é limitante. A identificação e a clonagem dos genes dos transportadores de alta afinidade poderão auxiliar os programas de melhoramento genético na obtenção de plantas mais eficientes na absorção de $\mathrm{N}$ em uma ampla faixa de disponibilidade deste nutriente no solo.

\section{REFERÊNCIAS BIBLIOGRÁFICAS}

ANGHINONI, I. Adubação nitrogenada nos estados do Rio Grande do Sul e Santa Catarina. In: SANTANA, M.B.M Adubação nitrogenada no Brasil. Ilhéus : CEPLAC/SBCS, 1986. Cap.I. p.1-18.

ASLAM, M., TRAVIS, R.L., HUFFAKER, R.C. Comparative kinetics and reciprocal inhibition of nitrate and nitrite uptake in roots of uninduced and induced barley (Hordeum vulgare L.) seedlings. Plant Physiology, Lancaster, v.99, p.1124$1133,1992$.

BEEVERS, L., HAGEMAN, R.H. Nitrate reduction in higher plants. Annual Review of Plant Physiology, Palo Alto, v.20, p.495-522, 1969.

BLOOM, A.J., SUKRAPANNA, S.S., WARNER, R.L. Root respiration associated with ammonium and nitrate absorption and assimilation by barley. Plant Physiology, Lancaster, v.99, p.1294-1301, 1992 
CRAWFORD, N.M. Nitrate: nutrient and signal for plant growth. The Plant Cell, Rockville, v.7, p.859-868, 1995.

CREGAN, P.B., BERKUM, P. Genetics of nitrogen metabolism and physiological/biochemical selection for increased grain crop productivity. Theoretical and Applied Genetics, Heidelberg, v.67, p.97-111, 1984.

DECKHARD, E.L., LAMBERT, R.J., HAGEMAN, R.H. Nitrate reductase activity in corn leaves as related to yields of grain and grain protein. Crop Science, Madison, v.13, p.343-350, 1973.

EICHELBERG, K.D., LAMBERT, R.J., BELOW, F.E., $\boldsymbol{e}$ t al. Divergent phenotipic recurrent selection for nitrate reductase in maize. I. Selection and correlated responses. Crop Science, Madison, v.29, p.1393-1397, 1989.

FAKOREDE, M.A.B., MOCK, J.J. Nitrate-reductase activity and grain yield of maize cultivar hybrids. Crop Science, Madison, v.18, p.680-682, 1978.

FENTEM, P.A., LEA, P.J., STEWART, G.R. Ammonia assimilation in the roots of nitrate- and ammonia-grown Hordeum vulgare (cv Golden Promise). Plant Physiology, Lancaster, v.71, p.496-501, 1983.

HAGEMAN, R.H., LAMBERT, R.J. The use of physiological traits for corn improvement. In: SPRAGUE, G.F., DUDLEY J.W. Corn and corn improvement. 3 ed. Madison : ASA/CSSA, 1988. Cap.7. p.431-461.

HAGEMAN, R.H., LENG, E.R., DUDLEY, J.W. A biochemical approach to corn breeding. Advances in Agronomy, New York, v.19, p.45-86, 1967.

HARPER, J.E. Nitrogen metabolism. In: BOOTE, K.J., BENNETT. J.M., SINCLAIR, T.R., et al. Physiology and determination of crop yield. Madison : ASA/CSSA/SSSA, 1994. Chapt.11 A. p.285-302.

HUANG, N., CHIANG, C., CRAWFORD, N.M., et al. CHL1 encodes a component of the low-affinity nitrate uptake system in Arabidopsis and shows cell type-specific expression in roots. The Plant Cell, Rockville, v.8, p.2183-2191, 1996.

HUPPE, H.C., TURPIN, D.H. Integration of carbon and nitrogen metabolism in plant and algal cells. Annual Review of Plant Physiology and Plant Molecular Biology, Palo Alto, v.45, p.577-607, 1994.

IMSANDE, J., TOURAINE, B. N Demand and regulation of nitrate uptake. Plant Physiology, Lancaster, v.105, p.3-7, 1994.

KING, B.J., SIDDIQI, Y., RUTH, T.J., et al. Feedback regulation of nitrate influx in barley roots by nitrate, nitrite, and ammonium. Plant Physiology, Lancaster, v.102, p.12791286,1993

LARSSON, C.M., INGEMARSSON, B. Molecular aspects of nitrate uptake in higher plants. In: WRAY, J.L., KINGHORN, J.R. Molecular and genetics aspects of nitrate assimilation. Oxford : Oxford Science, 1989. Chapt.1. p.3-14.

LEA, P.J. Nitrogen metabolism. In: LEA, P.J., LEEGOOD, R.C. Plant biochemistry and molecular biology. Chichester: John Wiley and Sons, 1993. Chapt.7. p.155-180.
LEA, P.J. Primary nitrogen metabolism. In: DEY, P.M., HARBORNE, J.B. Plant biochemistry. Academic, 1997. Chapt.7. p.273-313.

MACHADO, A.T., MAGALHÃES, J.R. Melhoramento de milho para uso eficiente de nitrogênio sob condições de estresse. In: SIMPÓSIO INTERNACIONAL SOBRE ESTRESSE AMBIENTAL: O MILHO EM PERSPECTIVA, 1995, Belo Horizonte, MG. Anais... Belo Horizonte : EMBRAPA/ CNPMS, 1995. 449p. p.321-343.

MACHADO, A.T., MAGALHÃES, J.R., MAGNAVACA, R., et al. Determinação da atividade de enzimas envolvidas no metabolismo do nitrogênio em diferentes genótipos de milho. Revista Brasileira de Fisiologia Vegetal, Campinas, v.4, n.1, p.45-47, 1992.

MAGALHÃES, J.R., FERNANDES, M.S. Absorção e metabolismo de nitrogênio sob condições de stress. In: SIMPÓSIO BRASILEIRO DE NITROGÊNIO EM PLANTAS, 1990, Rio de Janeiro, RJ. Anais... Rio de Janeiro : UFRRJ, 1990. 365p. p.249-262.

MAGALHÃES, J.R., MACHADO, A.T, FERNANDES, M.S., $\boldsymbol{e}$ al. Nitrogen assimilation efficiency in maize genotypes under ammonia stress. Revista Brasileira de Fisiologia Vegetal, Campinas, v.5, n.2, p.163-166, 1993.

MAGALHÃES, J.R., MACHADO, A.T. Biochemical parameters selecting maize for nitrogen assimilation efficiency under stress conditions. In: SIMPÓSIO INTERNACIONAL SOBRE ESTRESSE AMBIENTAL: O MILHO EM PERSPECTIVA, 1995, Belo Horizonte, MG. Anais... Belo Horizonte : EMBRAPA/CNPMS, 1995. 449p. p 345-367.

MIFLIN, B.J., LEA, P.J. The pathway of nitrogen assimilation in plants. Phytochemistry, New York, v.15, p.873-885, 1976.

OAKS, A., HIREL, B. Nitrogen metabolism in roots. Annual Review of Plant Physiology, Palo Alto, v.36, p.345-365, 1985.

OAKS, A. Efficiency of nitrogen utilization in $\mathrm{C}_{3}$ and $\mathrm{C}_{4}$ cereals. Plant Physiology, Lancaster, v.106, p.407-414, 1994.

PURCINO, A.A.C., MAGNAVACA, R., MACHADO, A.T., al. Atividade da redutase do nitrato em genótipos antigos e modernos de milho, cultivados sob dois níveis de nitrogênio. Revista Brasileira de Fisiologia Vegetal, Campinas, v.6, n.1, p.41-46, 1994

RUFTY, T.W., MACKOWN, C.T., VOLK, R.J. Effects of altered carbohydrate availability on whole-plant assimilation of ${ }^{15} \mathrm{NO}_{3}{ }^{-}$. Plant Physiology, Lancaster, v.89, p.457-463, 1989.

SCHRADER, L.E. Functions and transformations of nitrogen in higher plants. In: HAUCK, R.D. Nitrogen in crop production. Madison : ASA/CSSA/SSSA, 1984. Chapt.2. p.55-65.

SIDDIQI, M.Y., GLASS, A.D.M., RUTH, T.J., et al.. Studies of the uptake of nitrate in barley. I. Kinetics of ${ }^{13} \mathrm{NO}_{3}{ }^{-}$influx. Plant Physiology, Lancaster, v.93, p.1426-1432, 1990.

TOURAINE, B., GLASS, A.D.M. $\mathrm{NO}_{3}{ }^{-}$and $\mathrm{ClO}_{3}{ }^{-}$fluxes in the chl 1-5 mutant of Arabidopsis thaliana. Plant Physiology, Lancaster, v.114, p.137-144, 1997. 
TOURAINE, B., MULlER, B., GRIGNON, C. Effect of phloem-translocated malate on $\mathrm{NO}_{3}{ }^{-}$uptake by roots of intact soybean plants. Plant Physiology, Lancaster, v.99, p.1118 1123,1992

TURPIN, D.H., VANLERBERGHE, G.C., AMORY, A.M., et al. The inorganic carbon requirements for nitrogen assimilation. Canadian Journal of Botany, Ottawa, v.69, p.1139-1145, 1991.

ULLRICH, C.I., NOVACKY, A.J. Extra- and intracellular pH and membrane potential changes induced by $\mathrm{K}^{+}, \mathrm{Cl}^{-}, \mathrm{H}_{2} \mathrm{PO}_{4}^{-}$ $\mathrm{NO}_{3}{ }^{-}$uptake and fusicoccin in root hairs of Limnobium storoniferum. Plant Physiology, Lancaster, v.94, p.15611567,1990

VAN BEUSICHEM, M.L., KIRKBY, E.A., BAAS, R. Influence of nitrate and ammonium nutrition and the uptake, assimilation, and distribution of nutrients in Ricinu communis. Plant Physiology, Lancaster, v.86, p.914-921, 1988
VESSEY, J.K., RAPER, C.D., HENRY, L.T. Cyclic variations in nitrogen uptake rate in soybean plants: uptake during reproductive growth. Journal of Experimental Botany, New York, v.41, p.1579-1584, 1990.

VON WIRÉN, N., GAZZARRINI, S., FROMMER, W.B. Regulation of mineral nitrogen uptake in plants. Plant and Soil, The Hague, v.196, p.191-199, 1997.

WEGER, H.G., TURPIN, D.H. Mitochondrial respiration can support $\mathrm{NO}_{3}^{-}$and $\mathrm{NO}_{2}^{-}$reduction during photosynthesis. Plant Physiology, Lancaster, v.89, p.409-415, 1989.

WOO, K.C., OSMOND, B. Stimulation of ammonia and 2oxoglutarate-dependent $\mathrm{O}_{2}$ evolution in isolated chloroplasts by dicarboxylates and the role of the chloroplast in photorespiratory nitrogen recycling. Plant Physiology, Lancaster, v.69, p.591-596, 1982.

Ciência Rural, v. 30, n. 2, 2000. 